\title{
Small Airways Disease in Chronic Obstructive Pulmonary Disease: A 50 Years History
}

James C. Hogg, MD, $\mathrm{PhD}^{1,2}$ and Tillie-Louise Hackett, $\mathrm{PhD}^{1,3}$

${ }^{1}$ Centre for Heart Lung Innovation, St Paul's Hospital, University of British Columbia (UBC), ${ }^{2}$ Department of Pathology and Laboratory Medicine, UBC, and ${ }^{3}$ Department of Anesthesiology, Pharmacology and Therapeutics, UBC, Vancouver, Canada.

\section{ABSTRACT}

Macklem and Mead provided the first direct evidence that the small conducting airways $<2 \mathrm{~mm}$ in diameter accounted for less than $10 \%$ of the total lower airway resistance in 1967. This seminal report was followed by Hogg, Macklem, and Thurlbeck's 1968 report that confirmed and extended these observations by showing that the same small airways that offer so little resistance to airflow in normal human lungs become the major site of obstruction in patients with emphysema. These and other observations led Mead to postulate that these small conducting airways represent a "quiet" zone within the normal lung where disease can accumulate over many years without being noticed. This brief review revisits this hypothesis within the context of work reported in the 50 years since Macklem and Mead published their work. With special emphasis on why these small conducting airways are vulnerable to the development of disease. (BRN Rev. 2017;3:222-34) Corresponding author: James C. Hogg, Jim.Hogg@hli.ubc.ca

Key words: Chronic obstructive pulmonary disease. Host response. Particulate matter. Small airways disease. Tertiary lymphoid organ formation. 


\section{A HISTORICAL PERSPECTIVE OF SMALL AIRWAY DISEASE}

By the 1950's it was well understood that chronic bronchitis with or without emphysema was a major cause of death in the western world, but relatively little was understood about the basic pathology of this disease. In 1960, Fletcher et al. ${ }^{1,2}$ initiated an observational study of lung function, smoking habits, cough, sputum production and episodes of acute infection in a population of 1136 healthy working men between 30-59 years of age, of whom 792 completed an eight-year follow-up between 1961 and 1969. These results were summarized in an important monograph entitled "The natural history of chronic bronchitis and emphysema $^{3 \prime}$ in 1976 that discussed the causal links between smoking, chronic bronchitis, and emphysema. Up until the 1960's, both physiologists and clinicians accepted that the small airways were the major site of resistance in the lower respiratory tract in normal lungs, based on the calculations made by Rohrer (18881926) early in the $20^{\text {th }}$ century. This opinion began to change with the appearance of Weibel's ${ }^{4}$ classic monograph on the morphometry of the human lung, that showed that the total cross-sectional area of the airways increases exponentially as the gas exchanging surface is approached. This enabled Green ${ }^{5}$ to repeat Rohrer's calculations using Weibel's new data, to show that the small airways actually offer very little resistance to airflow. Shortly thereafter, Macklem and Mead ${ }^{6}$ provided the first direct experimental evidence showing that the small conducting airways offered very little resistance to airflow using a novel method that allowed them to partition the airway resistance located central and peripheral to the tip of a catheter placed in the $2 \mathrm{~mm}$ in diameter airways. This seminal report showed that instead of accounting for the bulk of the lower airways resistance as Roher had calculated, airways $<2 \mathrm{~mm}$ in diameter actually accounted for $<10 \%$ of the total resistance to flow below the laryn $x^{6}$. This report was followed by a second report by Hogg, Macklem, and Thurlbeck $^{7}$ in 1968 that showed the same airways that offered so little resistance to airflow in normal lungs became the major site of obstruction to airflow in post-mortem lungs from patients with emphysema ${ }^{7}$. In addition, the 1968 report also provided preliminary data on the nature of the disease in the small airways by using a combination of post-mortem bronchograms to show that, the lumens of smaller bronchi and bronchioles were narrowed and histology that showed these airways were affected by a mixture of chronic inflammation and fibrosis in the airway wall tissue and extensive plugging of the airway lumens by mucus containing inflammatory exudates ${ }^{7}$. In addition, these authors introduced the term "small airways disease" to describe these changes because they included both smaller bronchi defined by the presence of cartilage in their walls and bronchioles that have no cartilage in their walls. These and other data prompted Mead ${ }^{8}$ to write an influential editorial in 1970 that referred to the small airways $<2 \mathrm{~mm}$ in diameter as a "quiet" zone within normal adult lungs where disease can accumulate over many years without being noticed by either the persons affected or the physicians responsible for their care. This resulted in a rapid expansion of literature on the structure and function of the small airways that is reviewed in detail elsewhere', the purpose of this review is to focus on the factors that make the small airways vulnerable to the development of this disease. 


\section{A}

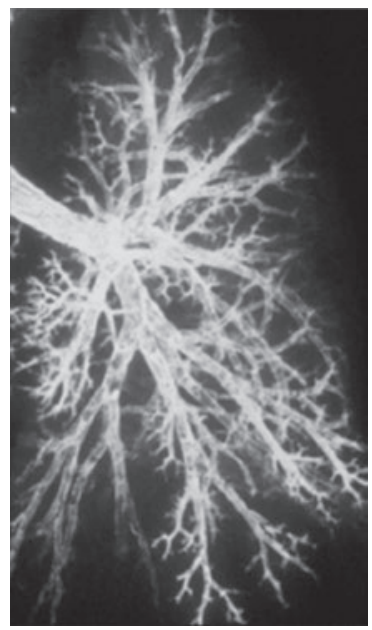

C

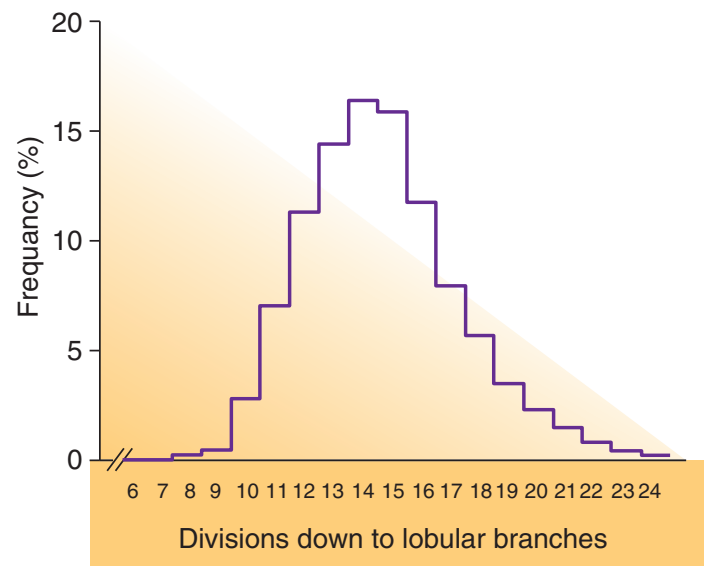

B

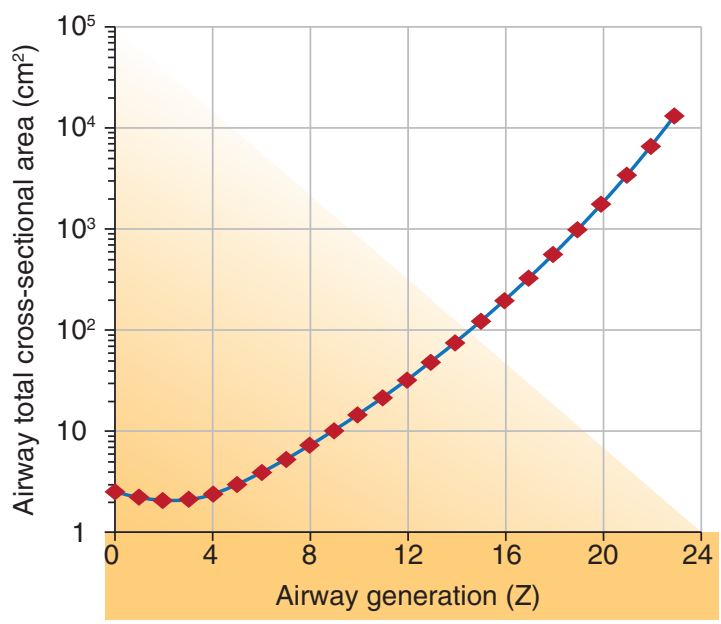

D

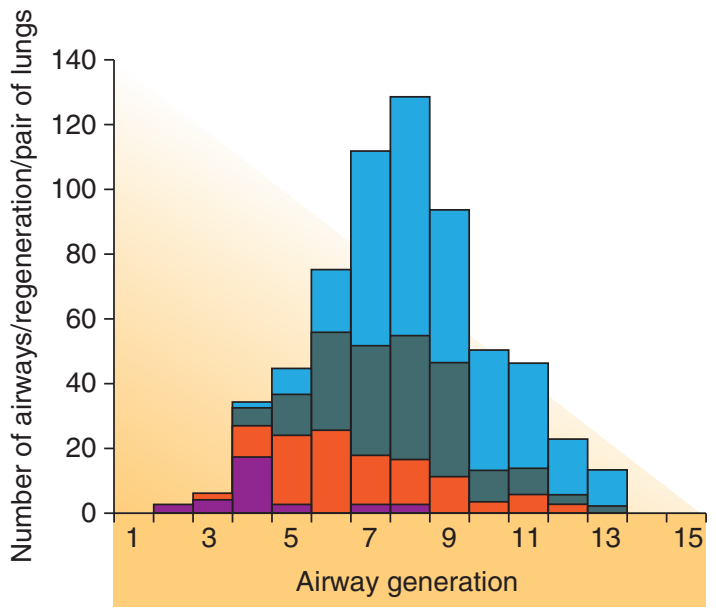

$\square 2 \mathrm{~mm} \square 2.5 \mathrm{~mm} \quad \square 3 \mathrm{~mm} \square 4 \mathrm{~mm}$

Figure 1. A) Bronchogram of a left lung to demonstrate the different pathway lengths to the periphery of the lung. B) The distribution of airways of a given size in each generation of branching to demonstrate that each generation contains airways of several different sizes (reproduced with permission from Weibel ER et al. ${ }^{4}$ ). C) The frequency of divisions from the trachea down to the lobular branches (reproduced with permission from Horsfield $K$ et al. ${ }^{46}$ ). D) Shows that the total lumen cross sectional area of all the branches decreases between generation 0-3 and then increases exponentially toward the periphery of the lung.

\section{SOME BASIC FACTS ABOUT LUNG ANATOMY}

The bronchogram of a normal left lung (Fig. 1A), shows that the pathways lengths from the trachea to the gas exchanging surface varies depending on the pathway taken, and figure $1 \mathrm{~B}$ provides data from Weibel's classic monograph on the morphometry of the human lung. That shows the total cross sectional area of all the airways at each generation of branching increases exponentially beyond 

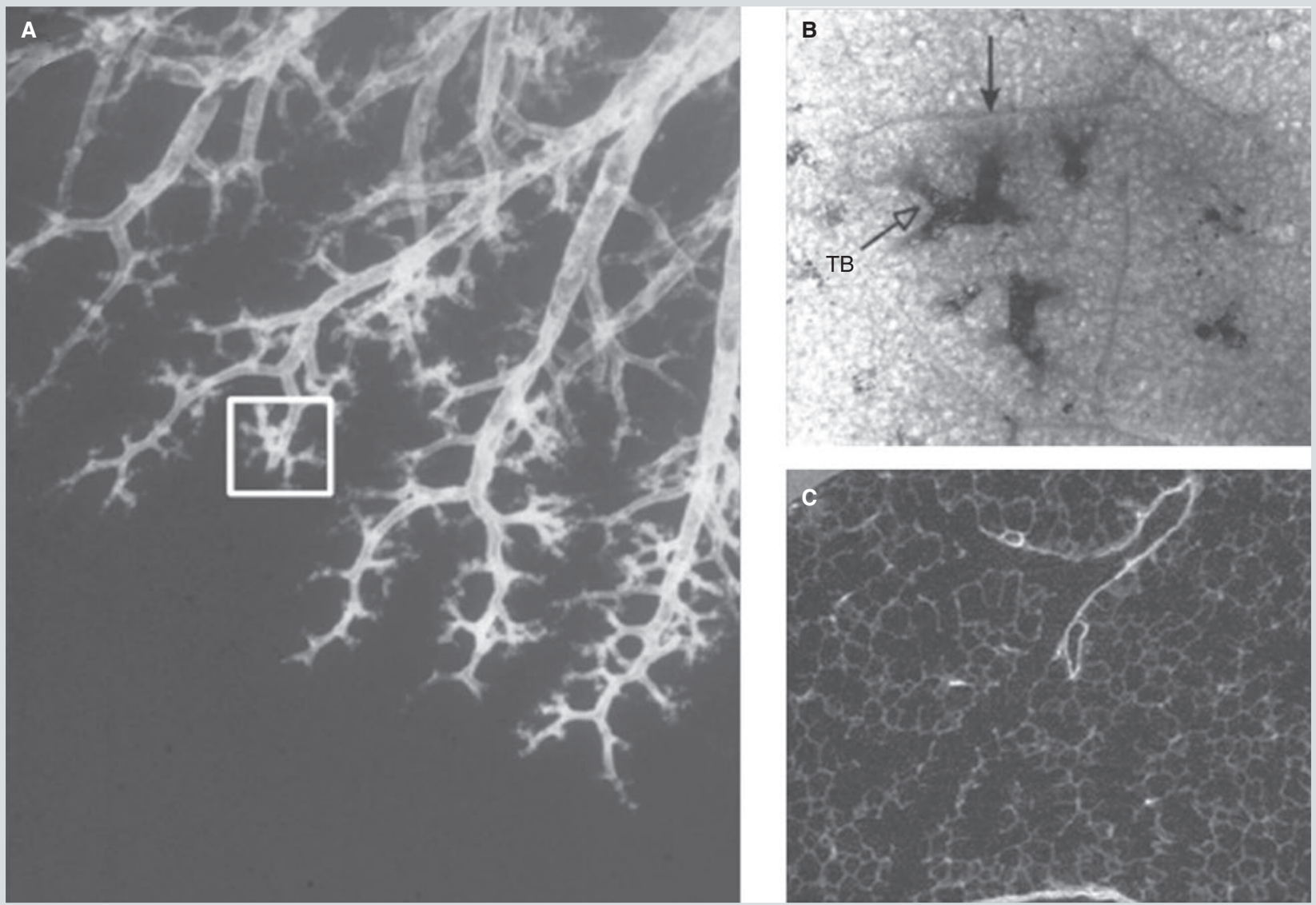

Figure 2. A) Bronchogram of the distal human lung to demonstrate Reid's original observation that in an individual pathway the airways branch points are initially centimetres apart, become closer to each other near the periphery of the lung and end in clusters of branches (white rectangles) that are only millimetres apart. B) An image of one of these clusters taken through the pleural surface to show that it represents a secondary lobule first described by Miller as a group of pre-terminal bronchioles surrounded by fibrous connective tissue septa (black arrow) and a terminal bronchiole (white arrowhead) that opens into a tuft shaped respiratory bronchiole. C) A micro computed tomography (CT) image at much higher magnification clearly demonstrates the junction between the terminal bronchiole and two first order respiratory bronchioles (also termed transitional bronchioles) where the alveoli opening from them are visible (reproduced with permission from Hogg JC et al. ${ }^{51}$ ).

the $4^{\text {th }}$ generation due to: 1 ) the rapid increase in their total number in the semi dichotomous branching airway tree; and, 2) the total cross sectional area of the two daughter branches is greater than the parent branch at each branching generation. Moreover, figure $1 \mathrm{C}$ provides quantitative information on the lengths of the pathways from the trachea to the lobular airways reported by Horsfield and Cumming ${ }^{10}$ showing they are normally distributed within the human lung. Lastly, figure 1D shows a replot of Weibel's data reported by McDonough et al. ${ }^{11}$ that confirms that each generation of airway branching contains airways of several different sizes. In addition, figure 2A illustrates the airway branching pattern that Reid ${ }^{12}$ used to separate the bronchi where the branches are roughly 
centimetres apart, from the clusters of ( $\mathrm{mm}$ ) branches that roughly identify the secondary lung lobules (originally described by Millar ${ }^{13}$ ) that are surrounded by a connective tissue septae (Fig. 2B). Each lobule contains multiple terminal bronchioles identified in a magnified view of the mm cluster (Fig. 2B) and observed in greater detail in a micro-computed tomography (microCT) image (Fig. 2C) previously reported by $\mathrm{McD}$ onough et $\mathrm{al.}{ }^{11}$. The microCT image clearly shows a terminal bronchiole dividing into two transitional bronchioles (i.e., first order respiratory bronchioles) where alveoli first appear.

Under normal resting conditions, the consumption of oxygen $\left(\mathrm{O}_{2}\right)$ and production of carbon dioxide $\left(\mathrm{CO}_{2}\right)$ by all of the bodies cells is balanced by breathing $500 \mathrm{ml}$ tidal volume of atmospheric gas into and out of the lungs at a rate of 10-15 times per minute. Where each $500 \mathrm{ml}$ tidal volume gas is moved into the lungs by bulk flow along a pressure gradient, generated by the active contraction of the respiratory muscles, that expand the thorax to lower alveolar pressure to bring gas into the lungs. In contrast, the bulk flow of gas out of the lungs is a passive process that moves gas by bulk flow out of the lungs along a pressure gradient created by release of the elastic force generated and stored in the lung and chest wall as they were stretched during inspiration. In addition, the gas in each tidal volume also moves by diffusion along concentration gradients that fully mix each $500 \mathrm{ml}$ in each tidal volume with the $3,000 \mathrm{ml}$ of residual gas that remains in the lungs at the end of expiration. Moreover, this process of diffusion along a concentration gradient is solely responsible for gas transport into and out of the pulmonary capillary blood across the very thin alveolar capillary membrane that separates the gas from the blood flowing through the lungs.

\section{THE NATURE OF ATMOSPHERIC PARTICULATE MATTER (PM)}

Particulate matter that is $10 \mu \mathrm{m}$ or less in diameter $\left(\mathrm{PM}_{10}\right)$ comes from a wide variety of sources, that include tree pollens, road dust, the burning of biomass fuel for cooking and heating, the harvesting and cleaning of grain, and a wide variety of other agricultural and industrial processes. In contrast, particulate matter $2.5 \mu \mathrm{m}$ or less in diameter $\left(\mathrm{PM}_{2.5}\right)$ are primarily generated from the exhaust of internal combustion engines, industrial processes that use a combination of heating and melting (i.e., smelting) to extract base metals from their ores and the natural burning of biomass fuels in forest fires. Although the particulate matter of all sizes enters the atmosphere, the time the particles remain suspended varies widely depending on their volume, mass, size, and shape. For example, particles with a diameter between 10 and $2.5 \mu \mathrm{m}$ remain suspended for relatively short periods (minutes to hours) and travel relatively short distances, whereas $\mathrm{PM}_{2.5}$ and smaller can remain suspended in the air for days, weeks and even months and travel hundreds to thousands of miles. Although this type of atmospheric contamination is a well-established risk factor for pulmonary and cardiovascular disease, this risk is relatively small in comparison to the risk associated with smoking tobacco. Where the high concentrations of toxic particles and gases present in each puff of tobacco smoke, are inhaled 
deeply into the lungs, to provide a repetitive source of tissue injury delivered from 20-30 cigarettes/day over periods that commonly last for 20-30 years. Thus, tobacco smoke has become a well-established risk factor for the development of lung cancer, chronic obstructive pulmonary disease (COPD), idiopathic pulmonary fibrosis (IPF) and other chronic lung diseases. Which is not surprising considering that tobacco smoke is known to contain as many as 4,700 different toxic substances ${ }^{14}$, ranging from milligram quantities of carbon oxides, nitrogen oxides, nicotine to picogram quantities of amides, free radicals, and heavy metals, volatile ketones, and nitriles.

\section{THE DEPOSITION OF PARTICULATE MATTER WITHIN THE LUNGS}

The exponential increase in total lumen cross sectional area of the airways in each generation of airway branching (Fig. 1), combined with the principle of the conservation of mass (i.e., bulk) flow, means that for whatever volume of gas moves through the larynx into the trachea over a given period of time, a similar volume of gas must move through all of the other generations of airway branches ${ }^{15}$. Therefore, the velocity of gas moving through the airways by bulk flow will progressively slow at each branching generation and stop after the volume of gas in the tidal breath has been accommodated in the residual lung volume. Which means that larger particles that develop the greatest momentum (mass $x$ velocity) will leave the flowing stream of gas and deposit by impaction in the nose, nasopharynx and larynx and the first few generations of tracheobronchial branching where the gas velocities remain high. In contrast, the intermediatesized particles that develop less momentum will deposit by impaction at branch points where the flow of gas changes direction and the finest particles that develop the least momentum will deposit in the regions of the lungs where the movement of gas shifts from bulk flow to diffusion. Based on Einstein's investigations on the theory of the Brownian movement ${ }^{16,17}$, that showed particles suspended in a gas diffuse much slower than the gases they are suspended in, we postulate that the terminal (the last generation of conducting airways) and transitional (the first generation of respiratory) bronchioles are particularly vulnerable to deposition of the finest particulate matter because they are located in the region of the lungs that accommodate the transition from bulk flow to diffusion.

\section{THE HOST RESPONSE TO INHALED PARTICULATE MATTER}

Although the hypothesis that particulate contamination of the atmosphere is harmful to human health is widely accepted, the precise mechanism(s) involved in translating the deposition of atmospheric particulates onto the lung surfaces and the development of disease in the respiratory and cardiovascular, as well as other body systems are poorly understood. The relationship between episodes of particulate air pollution and human health were initially established by identifying a relationship between episodes of atmospheric pollution and the increased appearance of patients with symptoms of disease in hospital emergency rooms. In addition, animal studies have shown phagocytosis of particulates deposited on the lung surface stimulates 

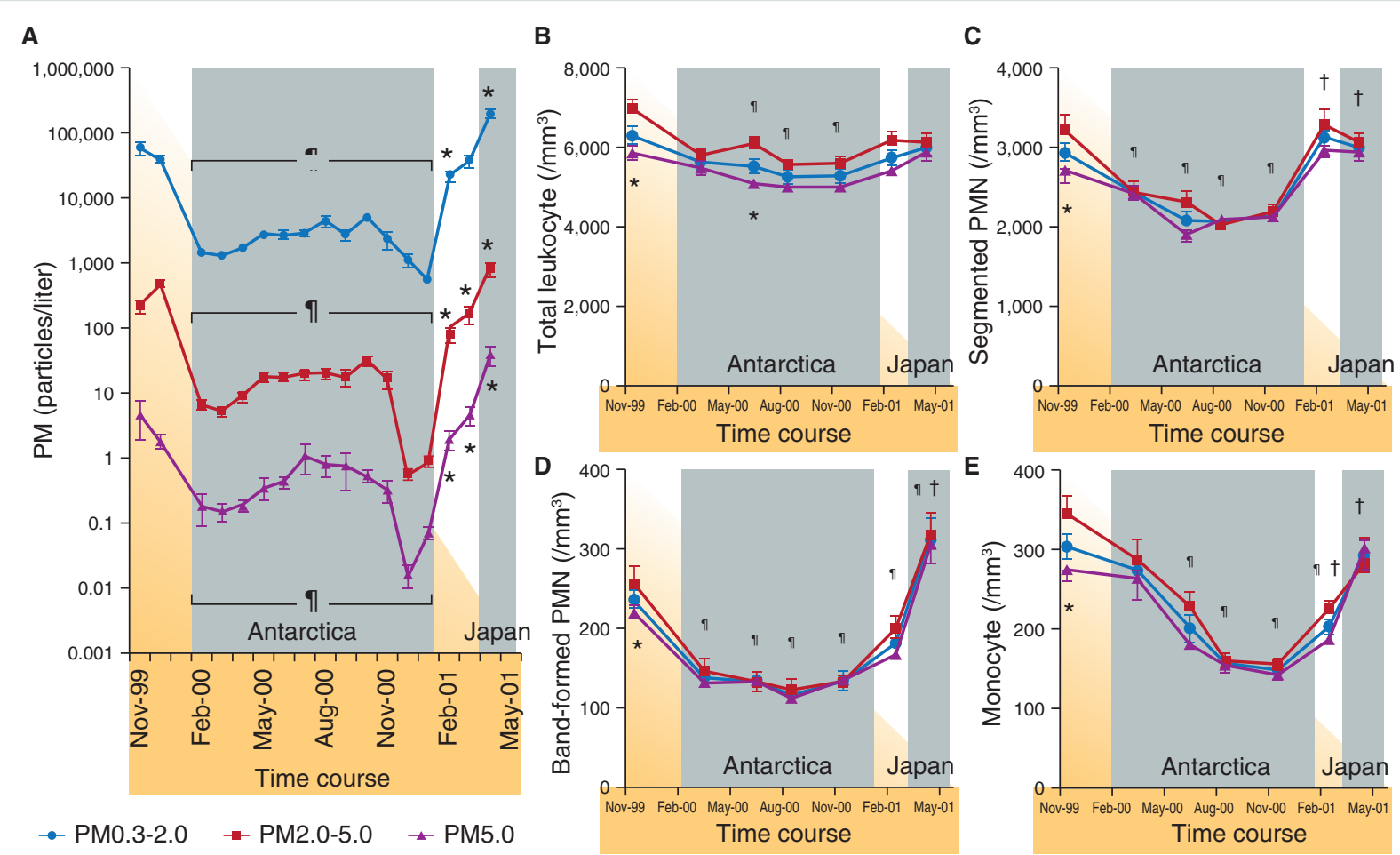

Shows the changes in atmospheric particulate air pollution during the 41 st Japanese expedition to the south pole. A) Shows the levels of (particle matters [PM] 0.3-0.2), (PM 2.0-5.0) and PM5.0 during the entire journey from Japan to Antarctica and return. B) Shows the total leucocyte count. C) Segmented polymorphonuclear leucocyte (PMN) count, D) Band-form PMN count that indicates the early release of PMN of the marrow, and E) shows the monocyte counts, over the same time periods that the air pollution was measured.

Although there were differences in leucocytes counts between smokers (red squares) and non smokers (purpletriangles) these differences (blue circles represent the difference between the two groups on which the differences over time were analyzed) tended to disappear in Antarctica where the levels of air pollution were very low (reproduced with permission from Sakai M et al. ${ }^{19}$ ).

PM: particle matters; PMN: polymorphonuclear leucocytes.)

the bone marrow to increase the levels of circulating leucocytes ${ }^{18}$ as part of a systemic response of the host. This research led to field studies that included the participants of the 41st Japanese Antarctic Research Expedition (JARE41). During the 12 month voyage from Japan to the Antarctic and back, the ship was equipped to measure PM continuously and the Physician on board was equipped to measure lung function with spirometry and collect regular blood samples from all
39 participants. In a study reported by Sakai et al. ${ }^{19}$, it was shown (Fig. 3A) that the concentration of $\mathrm{PM}_{2.5}$ fell from approximately 100,000/litre in Japan to just 1000/litre in Antarctica, remained at this level for the entire 12 months the group stayed in Antarctica, and returned to the control level during the return journey to Japan. Further, these data also show that this reduction in atmospheric pollution was associated with a modest reduction in total circulating white blood cell 
(WBC) counts (Fig. 3B), and more prominently, reductions in circulating polymorphonuclear leucocytes (PMN) (Fig. 3C), their band cell precursors (Fig. 3D) and that the circulating monocyte counts (Fig. 3E), followed a similar course. Further, the return to Japan was associated with a return to the levels of the levels atmospheric PM present on their departure was associated with a similar return of the circulating leucocyte levels similar to those observed on their departure from Japan to Antarctica the previous year. In addition, even though the smokers who continued to smoke during the entire voyage maintained the higher levels of circulating leucocytes expected in smokers compared to non-smokers, both smokers and non-smokers responded to the reduction in the concentration of atmospheric particulates by reducing their levels of circulating PMN, band cells and monocytes in the circulating blood.

In contrast to the effects of lowering atmospheric PM by relocating to Antarctica, the widespread forest fires in the Indonesian islands of Southern Kalimantan, Sumatra, and Java in 1997 provided Tan et al. ${ }^{20}$ with the opportunity to study the effects of an acute episode of atmospheric pollution. When the smoke from these fires enveloped Singapore with biomass-generated smoke containing high levels of gases (nitrogen dioxide $\left[\mathrm{NO}_{2}\right]$, ozone $\left[\mathrm{O}_{3}\right]$, and sulphur dioxide $\left[\mathrm{SO}_{2}\right]$ ) and ultrafine particles capable of passing through the filters of air-conditioned buildings and penetrating deep into the lungs (Fig. 4A), Tan et al. related publicly available data on atmospheric pollution to measurements of pulmonary function and circulating blood leucocytes counts in a group of 30 healthy young male volunteers (aged 19-24 years), who were participating in military training exercises as part of their National Service to Singapore $^{18,20}$. In the study they showed that this very brief episode of atmospheric pollution was associated with steadily increasing levels of circulating PMN leucocytes and band cell precursors (Fig. 4B) in the blood, until the haze reached its height, but these cells returned to normal control values as the haze cleared.

\section{THE LOCAL TISSUE RESPONSE IN LUNGS AFFECTED BY COPD}

Reports from several laboratories have shown that in comparison tissue from control subjects with normal lung function, the large and small conducting airways as well as the gas exchanging tissues from persons with mild (GOLD-1) and moderate (GOLD-2) COPD, in the 4-stage GOLD classification of COPD severity, are infiltrated with PMN, macrophages, CD4, CD8 and B cell lymphocytes. Further, one study that was able to compare lung tissue from patients at all four stages of the GOLD classification of $\mathrm{COPD}^{21}$ showed that, in addition to the lymphocyte dominant immune inflammatory infiltration observed in GOLD-1 and GOLD-2, severe GOLD-3 and very severe GOLD-4 COPD was associated with an abrupt increase in tertiary lymphoid organ formation ${ }^{21}$. Although, once considered a pathologic curiosity ${ }^{22}$, this pattern of histopathology is now recognized by the term "lymphoid neo-genesis with tertiary lymphoid organ formation" and has been implicated in the pathogenesis of a very wide range chronic inflammatory and autoimmune disease. That includes rheumatoid arthritis $^{23}$, Hashimoto's thyroiditis ${ }^{24}$, Sjogren's syndrome $^{25}$, chronic Lyme disease ${ }^{26}$ and many 

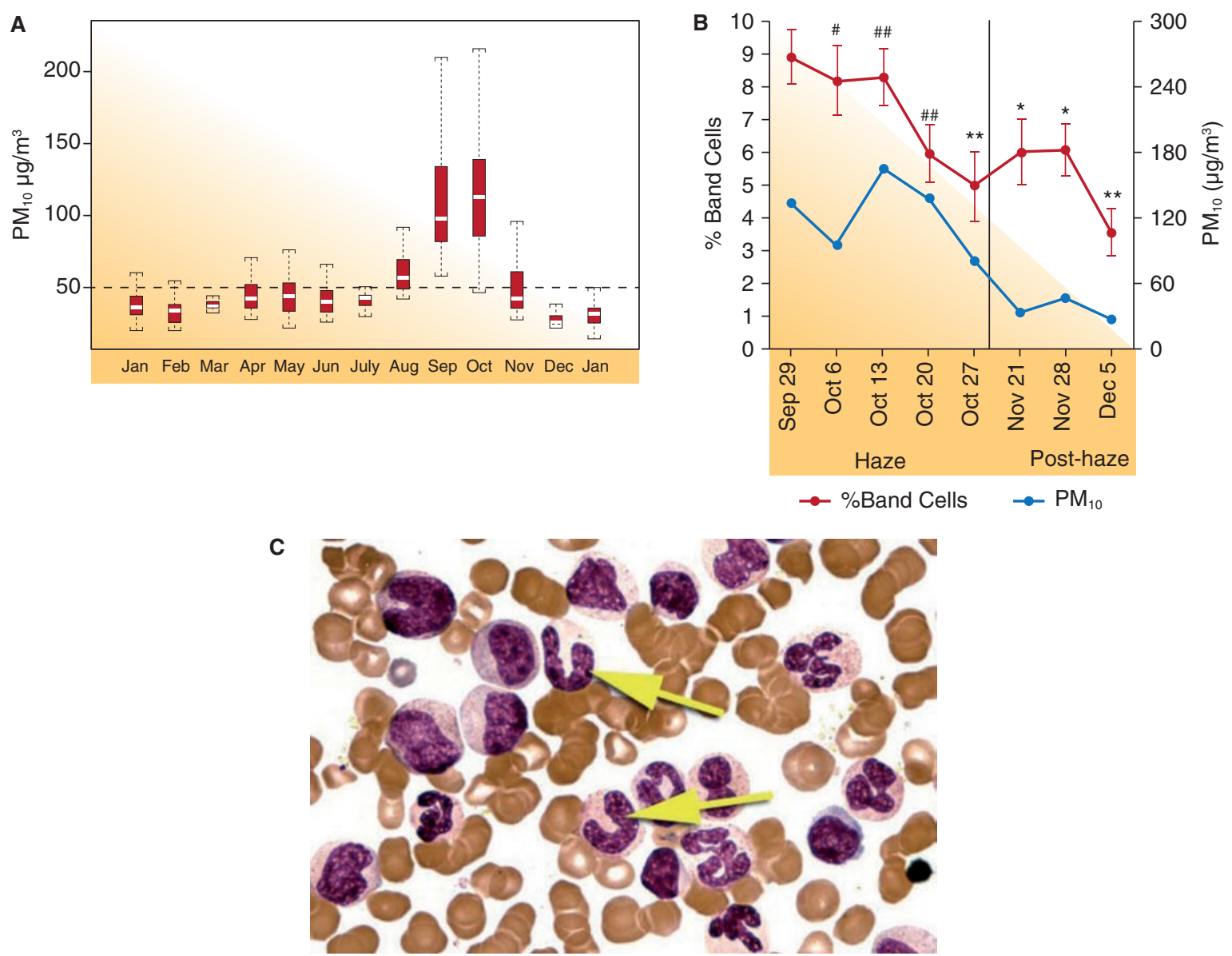

Figure 4. A) Shows a box and whisker plot of the levels of particulate matter $10 \mu \mathrm{m}$ or less in diameter $\left(\mathrm{PM}_{10}\right)$ air pollution in Singapore from January1996 to January 1997. To illustrate the sharp but still modest increase in air pollution that occurred between August and November due the Southeast Asian haze of 1997. B) Shows data from a group of military recruits that were undergoing basic training during the entire period of the haze where the data shows a clear association between circulating polymorphonuclear leucocytes (PMN) band cell forms and the level of particulate air pollution as the haze cleared. C) Shows a photomicrograph of the human bone marrow to illustrate the clear difference between band cell PMNs (black arrows) and mature PMNs (reproduced with permission from Tan WC et al. ${ }^{20}$ ). PM: particle matter; $\mathrm{PM}_{10}$ : particulate matter $10 \mu \mathrm{m}$ or less in diameter.

others diseases ${ }^{27}$. Although difficult to find in lung tissue from non-smokers, about 5\% of the airways examined in smokers with normal lung function contain tertiary lymphoid organs with no further increase observed in either mild (GOLD-1) or moderate (GOLD-2) COPD patients ${ }^{21}$. In sharp contrast, the number of airways containing tertiary lymphoid organs profiles increased sharply to $25-30 \%$ in severe and very severe COPD ${ }^{21}$. Further independent studies of tertiary lymphoid organs located in alveolar tissue in COPD $^{28,29}$, have also shown that these lymphoid follicles contain both memory and 
naïve B cells, $\mathrm{T}$ cells, plasmacytoid and follicular dendritic cells, that are required for $\mathrm{T}$ cell and B cell priming and clonal expansion in these tertiary lymphoid organs ${ }^{29}$. Moreover, the presence of these tertiary lymphoid organs provides definitive support for the presence of an adaptive immune response in the later stages of COPD. Furthermore, the observations that the B cell activating factor (BAFF), and lymphotoxin (TNF-LT) that are both members of the tumour necrosis factor (TNF) super family are upregulated in COPD implicated their role in regulating the development and maintenance of lymphoid follicles in $\mathrm{COPD}^{30}$. Further, as many of the B cell follicles within the tertiary lymphoid organs observed in COPD show evidence in keeping with the clonal expansion of the B cell populations with ongoing somatic hypermutation ${ }^{28}$. These findings strongly support the hypothesis that B cells in tertiary lymphoid organs are responding to antigens in COPD. Even though they provide no information about the antigens that are driving this response ${ }^{29}$.

\section{REMODELLING AND DESTRUCTION OF THE SMALL CONDUCTING AIRWAYS IN COPD}

The tissue remodelling and repair process that follows a single acute injury requires the activation of the coagulation system to control blood loss and seal the surface at the site of injury. This is followed by the activation of the acute inflammatory process to initiate the migration of the inflammatory immune cells into the site of injury to conduct the demolition process that precedes the onset of the tissue repair process and protects the site against infection, while the repair process attempts to restore the damaged tissue towards normal. By activating local fibroblasts, and encouraging the migration of both nearby myofibroblasts and circulating myocytes into the damaged tissue to form a complex network of fibres that contracts to reduce the volume of damaged tissue to make it easier for both epithelial and/or the mesothelial cells to migrate over the surface and restore its function as a protective barrier. In contrast, the repair of lung tissue that is repetitively damaged by the inhalation of the toxic particles and gases is infinitely more complex and prone to develop abnormal features that lead to several different pathological phenotypes of COPD.

Although several groups have reported associations between infiltration of the bronchiolar and alveolar tissue inflammatory immune cells and a decline in lung function ${ }^{21,31,39}$.

McDonough et al. ${ }^{11}$, were the first to successfully use microCT to show the terminal bronchioles are massively destroyed prior to the onset of emphysematous destruction in human lung tissue ${ }^{11}$. Further, Koo et al. ${ }^{40}$ from the same group, have recently shown that as many as $42 \%$ of the terminal bronchioles are already destroyed in lungs from patients with mild (GOLD-1) and moderate (GOLD-2) COPD severity who required resection of a either a lung or lobe as treatment for lung cancer, who had their lung function measured shortly before their surgery. Moreover, Suzuki et al. ${ }^{41}$ have also reported that this destruction of the terminal bronchioles is associated with an increase in collagen 1 and decrease in collagen 3 , consistent with scar formation, in regions of these very diseased lungs beforeemphysema 
formed. Further, this same group ${ }^{42}$ has recently shown that this early destruction of bronchiolar and alveolar tissue is associated with macrophage, CD4, CD8 and B cell lymphocyte infiltration with formation tertiary lymphoid organs ${ }^{42}$. And that genes associated with these infiltrating cells are enriched in the previously reported 127 gene expression signature associated with emphysematous destruction. Further, the within lung analysis recently reported by Suzuki et al. ${ }^{21}$ is consistent with a previously reported between lung analysis that first identified tertiary lymphoid organ formation in severe(GOLD-3) and very severe (GOLD-4) COPD.

In addition to the changes in the inflammatory immune response over the full range of COPD severity ${ }^{21}$, it has also been shown that there is extensive plugging of the airway lumens by inflammatory exudates that will not be further discussed, and fibrotic remodelling of the airway tissue ${ }^{21}$. Moreover, because this fibrotic process is extremely important to the pathology of COPD, the remainder of the space available will be used to discuss the fibroblasts that are a major group of interstitial cells within the lungs are an important source of growth factors, extracellular proteins, cytokines and enzymes, such as the metalloproteinases that are capable of remodelling interstitial, airway and alveolar tissue within the lungs ${ }^{43}$. Studies that have exposed human lung fibroblasts to cigarette smoke extract (CSE) have shown this leads to the induction of markers of oxidative stress and inflammation. Further, cigarette smoke has also been shown to adversely affect the ability of fibroblasts to proliferate and synthesize fibronectin and contract collagen- $\mathrm{I}^{45-47}$, all of which are important to normal tissue repair.
Campbell et al. ${ }^{48}$ were the first to link microCT measurements of emphysematous destruction to a 127-gene expression signature. In addition, Campbell et al. ${ }^{48}$ also found that the 127 genes associated with emphysematous destruction that were down regulated were associated with wound repair including integrin signalling, cytoskeletal contraction, extracellular matrix (ECM) production, vascular endothelial growth factor (VEGF) and transforming growth factor (TGF) and (TGF)- $\beta$ signalling. That these gene expression changes may have functional consequences in that fibroblasts from ex-smokers with severe COPD showed the deficient formation of focal adhesions and reduced ability to contract collagen-I gels compared to fibroblasts from former smokers without COPD ${ }^{48}$. Moreover, these findings have been replicated by other groups ${ }^{9,49}$. Fibrillar collagens, such as collagen I form, nanoscale ropes that are essential for providing tensile strength within the tissue, also act as a scaffold for elastic fibres as well as fibronectin, decorin, and associated proteins in the ECM. If defective radial collagen fibres are laid down within the small airways or parenchyma during repair, as these data suggest, a disruption of the mechanism by which the small airways are radially tethered by the alveolar walls would result. Further the observation that terminal bronchiolar destruction is well advanced in non-emphysematous regions of the lungs with very severe $\mathrm{COPD}^{11}$, and is already extensive in lungs from patients with mild to moderate COPD ${ }^{40}$ and end-stage COPD patients $^{11}$, is consistent with Mitzner's ${ }^{49}$ hypothesis that the destruction of the axial fibres that link large and small airways might contribute to small airway obstruction by shortening the small airways and decreasing 
the size of their lumens. Moreover, the ability of fibroblasts to arrange collagen into fibres disserves further investigation because it might have a significant effect on both radial and axial tethering.

\section{CONCLUSIONS}

This review is focused on the small conducting airways of the lung and why they are particularly vulnerable to the effects of inhaled particulates and gases that are suspended in tobacco smoke or pollution. Although much remains to be learned, we are encouraged by the rapid increase in new knowledge about the basic mechanisms involved in the pathogenesis of small airways disease that we propose precedes the onset of emphysematous destruction in COPD. Moreover we postulate that continued improvement in our understanding of the pathogenesis of small airways disease has the potential to assist in the development of new therapeutic strategies to prevent, arrest or reverse the debilitating effects of COPD.

\section{CONFLICT OF INTEREST}

\author{
Dr. James C. Hogg and Dr. Tillie-Louise Hackett \\ have nothing to disclose.
}

\section{REFERENCES}

1. Fletcher CM. Letter: Natural history of chronic bronchitis. Br Med J. 1976;1:1592-3.

2. Johnston RN, McNeill RS, Smith DH, Legge JS, Fletcher F. Chronic bronchitis-measurements and observations over 10 years. Thorax. 1976;31:25-9.

3. Fletcher CM, Peto R, Tinker C., Speizer FE. The natural history of chronic bronchitis and emphysema. $1^{\text {st }}$ ed. Oxford: Oxford University Press;1976.

4. Weibel ER. Morphometry of the Human Lung. New York, N.Y.: Academic Press Inc; 1963.
5. Green M. How big are the bronchioles? St Thomas Hosp Gaz. 1965;Sect.136-9.

6. Macklem PT, Mead J. Resistance of central and peripheral airways measured by a retrograde catheter. J Appl Physiol. 1967;22:395-401

7. Hogg JC, Macklem PT, Thurlbeck WM. Site and nature of airway obstruction in chronic obstructive lung disease. N Engl J Med. 1968;278:1355-60.

8 Hogg JC, Paré PD, Hackett TL. The Contribution of Small Airway Obstruction to the Pathogenesis of Chronic Obstructive Pulmonary Disease. Physiol Rev. 2017;97:529-52.

9. Mead J. The lung's “quiet zone”. N Engl J Med. 1970;282:1318-9.

10. Horsfield K, Cumming G. Morphology of the bronchial tree in man. J App Physiol. 1968;24:373-83.

11. McDonough JE, Yuan R, Suzuki M et al. Small-airway obstruction and emphysema in chronic obstructive pulmonary disease. N Engl J Med. 2011; 365:1567-75.

12. Reid L. The secondary lobule in the adult human lung, with special reference to its appearance in bronchograms. Thorax. 1958;13:110-5.

13. Miller WS. The Lung: Springfield; 1947.

14. Borgerding M, Klus H. Analysis of complex mixtures--cigarette smoke. Exp Toxicol Pathol. 2005;57 Suppl 1:43-73.

15. Potter MC, Wiggert DC. Schaum's Outline of Fluid Mechanics. USA: McGraw Hill;2008.

16. Einstein A. Investigations on the Theory of the Brownian Movement. Dover Publications; 1956 (1926).

17. Klafter J, Shlesinger MF, Zumofen G. Beyond Brownian Motion. Physics Today. 1996;33-9.

18. van Eeden SF, Tan WC, Suwa T et al. Cytokines involved in the systemic inflammatory response induced by exposure to particulate matter air pollutants (PM(10)). Am J Respir Crit Care Med. 2001;164:826-30.

19. Sakai M, Sato Y, Sato S et al. Effect of relocating to areas of reduced atmospheric particulate matter levels on the human circulating leucocyte count. J Appl Physiol.2004;97:1774-80.

20. Tan WC, Qiu D, Liam BL et al. The human bone marrow response to acute air pollution caused by forest fires. Am J Respir Crit Care Med, 2000;161: 1213-7.

21. Hogg JC, Chu F, Utokaparch S et al. The nature of small-airway obstruction in chronic obstructive pulmonary disease. N Engl J Med. 2004;350:2645-53.

22. Nagaishi C. Functional anatomy and histology of the lung: University Park Press; 1972.

23. Jones GW, Bombardieri M, Greenhill CJ et al. Interleukin-27 inhibits ectopic lymphoid-like structure development in early inflammatory arthritis. J Exp Med. 2015;212:1793-802.

24. Caturegli P, De Remigis A, Chuang K, Dembele M, Iwama A, Iwama S Hashimoto's thyroiditis: celebrating the centennial through the lens of the Johns Hopkins hospital surgical pathology records. Thyroid. 2013;23: 142-50.

25. Bombardieri M, Barone F, Lucchesi D et al. Inducible tertiary lymphoid structures, autoimmunity, and exocrine dysfunction in a novel model of salivary gland inflammation in C57BL/ 6 mice. J Immunol. 2012;189:3767-76.

26. Murray TS, Shapiro ED. Lyme disease. Clin Lab Med. 2010;30:311-28.

27. Jones GW, Hill DG, Jones SA. Understanding Immune Cells in Tertiary Lymphoid Organ Development: It Is All Starting to Come Together. Front Immunol. 2016;7:401.

28. van der Strate BW, Postma DS, Brandsma CA et al. Cigarette smoke-induced emphysema: A role for the B cell? Am J Respir Crit Care Med. 2006;173:751-8.

29. Brusselle GG, Demoor T, Bracke KR, Brandsma CA, Timens W. Lymphoid follicles in (very) severe COPD: beneficial or harmful? Eur Respir J. 2009; 34:219-30.

30. Polverino F, Baraldo S, Bazzan E et al. A novel insight into adaptive immunity in chronic obstructive pulmonary disease: B cell activating factor belonging to the tumor necrosis factor family. Am J Respir Crit Care Med. 2010; 182:1011-9.

31. Hogg JC, Timens W. The pathology of chronic obstructive pulmonary disease. Annu Rev Pathol. 2009;4:435-59. 
32. Cosio MG, Hale KA, Niewoehner DE. Morphologic and morphometric effects of prolonged cigarette smoking on the small airways. Am Rev Respir Dis. 1980;122:265-21.

33. Jeffery PK. Structural and inflammatory changes in COPD: a comparison with asthma. Thorax. 1998;53:129-36.

34. Mullen JB, Wright JL, Wiggs BR, Pare PD, Hogg JC. Reassessment of inflammation of airways in chronic bronchitis. Br Med J (Clin Res Ed). 1985;291: $1235-9$.

35. Saetta M, Di Stefano A, Maestrelli P et al. Activated T-lymphocytes and macrophages in bronchial mucosa of subjects with chronic bronchitis. Am Rev Respir Dis. 1993;147:301-6.

36. Saetta M, Di Stefano A, Turato G et al. CD8+ T-lymphocytes in peripheral airways of smokers with chronic obstructive pulmonary disease. Am J Respir Crit Care Med. 1998;157:822-6.

37. Saetta M, Turato G, Baraldo S et al. Goblet cell hyperplasia and epithelial inflammation in peripheral airways of smokers with both symptoms of chronic bronchitis and chronic airflow limitation. Am J Respir Crit Care Med. 2000;161:1016-21.

38. Saetta M, Turato G, Facchini FM et al. Inflammatory cells in the bronchial glands of smokers with chronic bronchitis. Am J Respir Crit Care Med. 1997;156:1633-9.

39. Finkelstein R, Fraser RS, Ghezzo H, Cosio MG. Alveolar inflammation and its relation to emphysema in smokers. Am J Respir Crit Care Med. 1995; 152:1666-72.

40. Koo H.K, Vasilescu DM, Scott AE et al. Micro-CT Analysis Of Paraffin Embedded Lung Tissue: Is Small Airway Obstruction An Early Feature Of COPD? Am J Respir Crit Care Med. 2015;191.
41. Suzuki M, Elliot WM, McDonough JE et al. The quantitative relationship between collagen deposition and lung structure in COPD. Am J Respir Crit Care Med. 2010;181:A6808.

42. Suzuki M, Ma S, Campbell JD et al. The cellular and molecular determinants of emphysematous destruction in COPD. Sci Rep. 2017

43. Stone PJ, Morris SM, Thomas KM, Schuhwerk K, Mitchelson A. Repair of elastase-digested elastic fibers in acellular matrices by replating with neonatal rat-lung lipid interstitial fibroblasts or other elastogenic cell types. Am J Respir Cell Mol Biol. 1997;17:289-301.

45. Carnevali S, Petruzzelli S, Longoni B et al. Cigarette smoke extract induces oxidative stress and apoptosis in human lung fibroblasts. Am J Physio Lung Cell Mol Physiol. 2003;284:L955-63.

46. Wang $\mathrm{H}$, Liu X, Umino $\mathrm{T}$ et al. Cigarette smoke inhibits human bronchial epithelial cell repair processes. Am J Respir Cell Mol Biol. 2001;25:772-9.

47. Carnevali S, Nakamura Y, Mio T et al. Cigarette smoke extract inhibits fibroblast-mediated collagen gel contraction. Am J Physiol. 1998;274:L591-8.

48. Nakamura Y, Romberger DJ, Tate L et al. Cigarette smoke inhibits lung fibroblast proliferation and chemotaxis. Am J Respir Crit Care Med. 1995 151:1497-503.

49. Campbell JD, McDonough JE, Zeskind JE et al. A gene expression signature of emphysema-related lung destruction and its reversal by the tripeptide GHK. Genome Med. 2012;4:67.

50. Mitzner W. Emphysema--a disease of small airways or lung parenchyma? N Engl J Med. 2011;365:1637-9.

51. Hogg JC, Paré PD, Hackett TL. The Contribution of Small Airway Obstruction to the Pathogenesis of Chronic Obstructive Pulmonary Disease. Physiol Rev. 2017; 97:529-52. 